\title{
Isolation and Characterization of Novel Yeasts From Dairy Cattle Rumen for Potential Use as Feed Additives
}

Chanon Suntara

Khon Kaen University

Anusorn Cherdthong ( $\nabla$ anusornc@kku.ac.th )

Tropical Feed Resources Research and Development Center (TROFREC), Department of Animal Science, Faculty of Agriculture, Khon Kaen University, Khon Kaen 40002, Thailand

Metha Wanapat

Khon Kaen University

Suthipong Uriyapongson

Khon Kaen University

Vichai Leelavatcharamas

Khon Kaen University

Jutaporn Sawaengkaew

Khon Kaen University

Pin Chanjula

Prince of Songkla University

Suban Foiklang

Maejo University

\section{Research Article}

Keywords: Novel rumen yeast, Screening, Isolation, Yeast biomass of yeast, Cellulase enzyme, Dairy cattle

Posted Date: November 24th, 2020

DOl: https://doi.org/10.21203/rs.3.rs-107015/v1

License: (c) (i) This work is licensed under a Creative Commons Attribution 4.0 International License.

Read Full License 
1 Isolation and characterization of novel yeasts from dairy cattle rumen for potential use

2 as feed additives

3 Chanon Suntara ${ }^{1}$, Anusorn Cherdthong ${ }^{1 *}$, Metha Wanapat ${ }^{1}$, Suthipong Uriyapongson ${ }^{1}$, Vichai

4 Leelavatcharamas ${ }^{2}$, Jutaporn Sawaengkaew ${ }^{3}$, Pin Chanjula ${ }^{4}$, Suban Foiklang ${ }^{5}$

6 Affiliations

$7 \quad{ }^{1}$ Tropical Feed Resources Research and Development Center (TROFREC), Department of 8 Animal Science, Faculty of Agriculture, Khon Kaen University, Khon Kaen 40002, Thailand

$9{ }^{2}$ Fermentation Research Center for Value Added Agricultural Products (FerVAAP), 10 Department of Biotechnology, Faculty of Technology, Khon Kaen University, Khon Kaen 11 40002, Thailand

$12{ }^{3}$ Department of Microbiology, Faculty of Science, Khon Kaen University, Khon Kaen 40002, 13 Thailand

$14{ }^{4}$ Department of Animal Science, Faculty of Natural Resources, Prince of Songkla University, 15 Songkhla 90112, Thailand

${ }^{5}$ Faculty of Animal Science and Technology, Maejo University, Chiangmai 50290, Thailand

*Corresponding author; anusornc@kku.ac.th; Tel: +66-83-287-7374 
The aims of this study were to screen and isolate yeast which is producing high biomass and cellulase enzyme from rumen fluid. Two fistulated Thai crossbred Holstein Friesian steers, averaging $350 \pm 20 \mathrm{~kg}$ body weight, were used. The experiments were designed by $12 \times 3 \times 3$ factorial arrangement in a completely randomized (CRD). Factor A was isolated yeasts (11 difference characteristics) and S. cerevisiae. Factor B was sugarcane molasses (M) concentration $(50,150$, and $250 \mathrm{~g} / \mathrm{L})$. Factor $\mathrm{C}$ was urea $(\mathrm{U})$ concentration $(10,30$, and $50 \mathrm{~g} / \mathrm{L})$ (experiment 1). To assess biochemical properties, the potential yeast were selected for identified and analyzed. The highest yeast biomass was observed in three yeasts including codes H-KKU20, I-KKU20, and C-KKU20. The highest CMCase activity was observed in yeast code H-KKU20. Identification of isolates H-KKU20 and I-KKU20 revealed that those isolates belonged to Pichia kudriavzevii-KKU20 and Candida tropicalis-KKU20, while CKKU20 was identified as Galactomyces sp.-KKU20. The $P$. kudriavzevii-KKU20 and $C$. tropicalis-KKU20 provided maximum cell growth. The highest ethanol production was observed in S. cerevisiae. The $P$. kudriavzevii-KKU20 yielded the least reducing sugar. $P$. kudriavzevii-KKU20 had higher results than the other yeasts in terms of yeast biomass production, cellulase enzyme activity, and cell number. This species may lead to higher production of yeast cell wall than the traditional species in yeast industry (such as $S$. cerevisiae) or in other applications as ruminant feed additives.

Keywords: Novel rumen yeast, Screening, Isolation, Yeast biomass of yeast, Cellulase enzyme, Dairy cattle

\section{Introduction}

The use of yeast in ruminant nutrition has been a common practice for over four decades now, the theoretical modes of action of yeast in the rumen environment have been described 
extensible by Fonty and Chaucheyras-Durand ${ }^{1}$ and other, albeit these are not always consistent. Therefore it could be hypothesized that feeding yeast to ruminant could be growth promoting. The mode of yeast action in the rumen depends on many factors such as diet composition, viability, and strain of yeast ${ }^{2}$. Many studies have suggested a commercial strain such as $S$. cerevisiae a single cell protein supplement in animal feed; however, potential feed utilization remains limited, particularly the low of yeast biomass and fibrolytic enzyme production.

Previous studies have shown the capability of ruminal yeast strains when supplemented in ruminant diets. Although the study by Sirisan et al. ${ }^{3}$ successfully isolated yeast strains they didn't evaluate its effects on the rumen $\mathrm{pH}$ of dairy cattle, they only hypostatized and suggested that this could be the case and as reported by extensive literature the effect of yeast supplementation on reticulo-ruminal $\mathrm{pH}$ has resulted in variable results e.g. Hasunuma et al. ${ }^{4}$. Moreover, Paserakung et al. ${ }^{5}$ revealed that Tricosporon asahii GSY10, a yeast isolated from the environment, was a potential alternative fat source in ruminant diets. A recent study by Intanoo, et al. ${ }^{6}$ reported that isolated Kluyveromyces marxianus yeast from rumen fluid showed potential as an aflatoxin-detoxifying agent in dairy cattle. In addition, there are some study have been described yeast could be produce cellulase enzymes such as Tricosporon cutaneum ${ }^{7}$. Sarawan $^{8}$ discovered a new yeast species, namely Candida konsanensis KKU-FW10, isolated from the Jasminum adenophyllum plant. C. konsanensis could potentially produce 58.24 units/ml of carboxymethyl cellulase (CMC) according to an in vitro study. However, to our knowledge there are no reports of existing yeast producing cellulase enzyme and high yeast biomass synthesis in the rumen of ruminants. We hypothesized that rumen fluid with yeast producing cellulase enzyme can occur and also produces a high yeast biomass compared to $S$. cerevisiae.

Therefore, the aim of this study was to screen and isolate yeast from rumen fluid with an experimental design method. We optimized a fermentation medium containing sugarcane 
molasses as a carbon source and urea as a nitrogen source to measure the efficiency of yeast biomass production and cellulase activity.

\section{Results}

\section{Isolation and morphological characteristics of yeast isolated from rumen fluid}

Isolation was under aerobic conditions, resulting in a total of 11 different colonies, whose colony morphology and microscopic observations are shown in Table 1 . The 11 isolates of yeast were grown on YM agar plates and selected for formed appearance, elevation, colony nature, and colony color. The budding stage of the isolated yeast was observed under (40x) microscope and the colonies were confirmed to be yeast as, shown in Table 1. We noted two appearances of colonies including, asymmetric (indicated as A, B, C, E, and J) and ovoid colonies (coded as D, F, G, H, I, and K). In addition, elevations of colonies are indicated as A and B, whereas flat colonies are coded as C, D, E, I, and J, and convex colonies are indicated as F, G, H, and K. Smooth colonies are coded as D, E, I, and J, while other codes correspond to rough. Most colonies in this study showed white color, except codes D and J, which were colourless and code $\mathrm{G}$ was turbid.

\section{The yeast biomass production and cellulase activity}

Effects of varying concentrations of sugarcane molasses and urea on yeast biomass of isolated yeast

Interactions were observed between yeast strains and sugarcane molasses with urea on yeast biomass production and the results are shown in Figure 1. Yeast biomass production from ruminal isolated yeast was observed from 3.19 to $17.08 \mathrm{~g} / \mathrm{L}$ in all media solutions. The highest yeast biomass was observed in three yeasts including codes H-KKU20, I-KKU20, and CKKU20 when inoculated in $250 \mathrm{~g} / \mathrm{kg}$ molasses with $10 \mathrm{~g} / \mathrm{kg}$ urea (M25+U1) which provided 
the highest yeast biomasses level at $15.77,17.08$, and $16.71 \mathrm{~g} / \mathrm{L}$, respectively $(P<0.01) . S$. cerevisiae with $\mathrm{M} 25+\mathrm{U} 1$ produced a yeast biomass of $16.16 \mathrm{~g} / \mathrm{L}(P<0.01)$.

\section{Effects of varying concentrations of sugarcane molasses and urea on cellulase activity} of isolated yeast

Interactions were observed between yeast strains and sugarcane molasses with urea on carboxymethyl cellulase activity, and the results are shown in Figure 2. From 0 to 0.101 units/ml CMCase activity was observed in all media solutions. The highest CMCase activity was observed in yeast code $\mathrm{H}-\mathrm{KKU} 20$ when inoculated in all media solutions, providing a cellulase activity range from 0.041 to 0.101 units $/ \mathrm{ml}(P<0.01)$. Yeast code H-KKU20 inoculant in $250 \mathrm{~g} / \mathrm{kg}$ molasses with $30 \mathrm{~g} / \mathrm{kg}$ urea provided the maximum CMCase activity (0.101 ml/unit)

(1)

\section{Selection and identification of potential yeast strains}

Ruminal yeasts strains H-KKU20, I-KKU20, and C-KKU20 were selected for their ability to produce yeast biomass and their CMCase enzyme synthesis.

The newly isolated yeast strain was identified via DNA sequencing ${ }^{10}$ using $26 \mathrm{~S}$ rRNA gene D1/D2 domain. Identification of isolates H-KKU20 and I-KKU20 revealed that those isolates belonged to Pichia kudriavzevii-H-KKU20 and Candida tropicalis-I-KKU20, respectively. The D1/D2 sequence of C-KKU20 had $99.82 \%$ (1 nucleotide substitution) similarity with the undescribed species Galactomyces sp. HN21-4 (EU651849) (name changes: Geotrichum sp. HN21-4) and was closest to the Galactomyces geotrichum strain NRRL Y17569T (NG_054826), but with 11 nucleotide substitutions and 1 one gap. Based on the sequence of the D1/D2 region, strain C-KKU20 was identified as Galactomyces sp.-C-KKU20 (Table 2). 
Cell counts, ethanol production and reducing sugar by ruminal yeast strains

0.05) and cell count are shown in Figure 3. Interactions were observed between incubation time and isolated yeast strains $(P<0.01)$. Yeast cell were counted at 6.24 to $10.02 \mathrm{Log}$ cells $/ \mathrm{ml}$ at 0 to $72 \mathrm{~h}$ of incubation time. Two strains provided maximum cell growth: $P$. kudriavzevii-HKKU20 (9.78 and 10.02 Log cell/ml) and C. tropicalis-I-KKU20 (9.53 and 9.6 Log cells/ml) growth at 60 and $72 \mathrm{~h}$ of incubation time, respectively.

Interaction effects were observed between incubation time and isolated yeast strains $(P$ $>0.05$ ) on reducing sugar (result shown in Figure 5). The isolated yeast yielded reducing sugar 

yielded the least reducing sugar about 30.6 and $29.8 \mathrm{~g} / \mathrm{L}$ at 60 and $72 \mathrm{~h}$ of incubation time, respectively. Meanwhile, the two strains that yielded the most reducing sugar were Galactomyces sp.-I-KKU20 and S. cerevisiae at 60 and $72 \mathrm{~h}$ of incubation time, respectively.

\section{Discussions}

Yeast was reported as a member of the ruminal microbial population, as discovered by

Orpin $^{22}$. In this study, yeast was isolated from rumen fluid of Holstein-Friesian dairy cattle.

Rumen fluid was cultured under aerobic conditions, which yielded 11 yeast isolates. Similar, with $\operatorname{Sirisan}^{9}$ that 10 isolated yeasts were present when dairy cattle were fed a high-concentrate diet, while 7 isolates were present when the cattle were fed a mixture of a high proportion of fermented cassava pulp and concentrate. In addition, Intanoo et $a l .{ }^{6}$ fed cattle rice straw, cassava pulp, and distilled yeast sludge. The presence of 7 to 10 yeast isolates was found when cultured under aerobic conditions.

In terms of morphology, yeast isolates were ovoid (6 in 11), flat (5 in 11), convex (4 in 11), or rough (7 in 11). White colonies (9 in 11) appeared most frequently. The morphology of the yeasts observed in our study were similar to those reported Marrero et al. ${ }^{23}$, who concluded that the yeast morphologies were slightly convex, smooth, and white- to creamcolored, which is typical of ruminal yeast. However, many factors might cause different types coloration, which was later discovered to be Levica strains 18 (L18). Thus, the morphological characteristics of ruminal yeast colonies can be quite complex.

To increase the yeast biomass of yeast, a substrate such as soluble carbohydrate and nitrogen must provide sufficient supplies for the growth of yeast cells ${ }^{25}$. Paserakung et al. ${ }^{5}$ 
reported that increasing molasses concentration from 80 to $160 \mathrm{~g} / \mathrm{L}$ resulted in the greatest yeast biomass production of $25.9 \%$ obtained from Trichosporon asahii. In addition, Johnson et al..$^{12}$, who studied the effects of different single-substrate carbon sources such as molasses, glucose, and sucrose with limited nitrogen sources in media solutions on the yeast biomass production of Rhodotorula glutinis IIP-30, found that yeast biomass production increased by $87.8 \%$ in molasses treatment. Thus, molasses might be a better potential carbon source for yeast growth than other carbon sources. Our media solution contained molasses $250 \mathrm{~g} / \mathrm{L}$ with urea $10 \mathrm{~g} / \mathrm{L}$, providing a maximum ruminal yeast yeast biomass of $29.2 \%$. This could signify that providing optimum levels of molasses and urea could positively affect yeast biomass production. Manikandan and Viruthagiri ${ }^{26}$ reported that the nitrogen source, concentrate of nitrogen, and carbon-/ nitrogen ratio (C:N ratio) also influenced the production of yeast biomass. Danesi et al. ${ }^{27}$ demonstrated that the use of sugarcane blackstrap molasses and yeast extract at a carbon to nitrogen ratio of $10: 1(\mathrm{C}: \mathrm{N}$ is 10$)$ provided the greatest yeast biomass of yeast. In addition, Sokchea et al. ${ }^{28}$ found that yeast biomass of yeast was highest at $7.57 \mathrm{~g} / \mathrm{L}$ when the $\mathrm{C}: \mathrm{N}$ ratio reached 10:1. However, when compare to our study, $\mathrm{C}: \mathrm{N}$ ratio was higher results about 25:1. This ratio might suitable to produce highest yeast biomass $(17.07 \mathrm{~g} / \mathrm{L})$.

For yeast, the major factor influencing the production of yeast biomass is not just the supplied carbon and nitrogen. Previous studies have shown that yeast strains have a significant impact on the production of yeast biomass. Van Urk et al. ${ }^{29}$ reported that $S$. cerevisiae had low potential to proliferate under excessive glucose, even with aerobic conditions. Wardrop et al..$^{30}$ found that Kluyveromyces marxianus provided a higher yeast biomass 7 times greater than $S$. cerevisiae when cultured in a media solution with excessive glucose. Under aerobic conditions, oxygen acts as the final electron acceptor and if yeasts complete metabolism like $P$. kudriavzevii-H-KKU20 and C. tropicalis-I-KKU20 as shown in this study, they will be produce high yeast biomass and less alcohol which is called "Crabtree-negative yeast". In contrast, $S$. 
cerevisiae exhibits alcoholic fermentation and produces high amounts of ethanol, which is called "Crabtree-positive yeast" 31 . The above explanation seems to be the reason that support why $P$. kudriavzevii-H-KKU20 and $C$. tropicalis-I-KKU20 produced greater yeast biomass more than S. cerevisiae.

In this study, the isolated yeast produced and released cellulase enzymes ranging from 0.020 to 0.075 units $/ \mathrm{ml}$. This finding can allow us to add this particular property to animal feed. Although to our knowledge studies on the release of cellulase enzymes by yeast from the rumen have not been conducted, studies from natural yeast have demonstrated that yeast could produce cellulase enzymes. Sarawan ${ }^{8}$ who revealed that Candida glabrata, Candida natalensis and Kluyveromyces africanus (isolated the from Jasminum adenophyllum plant), when cultured in yeast extract peptone dextrose broth with $10 \mathrm{~g} / \mathrm{kg} \mathrm{CMC}$, have the ability to release cellulase enzymes ranging from 0.004 to 0.08 units $/ \mathrm{ml}$. Thus, cellulase enzymes produced by yeasts might be a potential digest feed containing cellulose contents. As for the mechanism by which yeast digests fiber, it is generally known that cellulose is hydrolyzed by the cellulase enzymes system, as it breaks down the $\beta-1,4$-glycosidic bonds ${ }^{32}$. Cellobiohydrolases (CBHs, EC 3.2.1.91) are important cellulase enzymes found in yeast. CBHs are instrumental in highperformance, natural cellulose hydrolysis ${ }^{33}$. Examples of $\mathrm{CBH}$ expressed in yeast include CBH1 (Cel7A) and CBH2 (Cel6A) ${ }^{34}$.

Our study demonstrated that three yeasts were isolated from rumen fluid: P. kudriavzeviiH-KKU20, C. tropicalis-I-KKU20, and Galactomyces sp.-C-KKU20. The name KKU refers to Khon Kaen University, where the strain was originally isolated, and the number " 20 " means the year of discovery, 2020. Interestingly, the similar yeast species of P. kudriavzevii, C. tropicalis, and Galactomyces sp. had previously been isolated ${ }^{35-37}$. However, qualities of these strains have not been studied, and this is the first report characteristic such as yeast biomass production, cellulase activity, growth patterns, ethanol production, and reducing sugar of yeast 
from rumen have been studied in them. In addition, the types of potential yeast were Crabtreenegative. Crabtree-negative yeasts $P$. kudriavzevii-H-KKU20 and $C$. tropicalis-I-KKU20 can more rapidly convert available sources of carbon into a solution for yeast biomass. A category of yeast may therefore be used as an alternative to improving feed or use as a feed additive in ruminant animals, rather than the conventional yeast such as $S$. cerevisae.

Our results showed that the Pichia kudriavzevii-H-KKU20 inoculants in media solution can grow greater than other species. The maximum yeasts growth was $10.02 \mathrm{Log}$ cells $/ \mathrm{ml}$ in aerobic conditions at $72 \mathrm{~h}$ of incubation. Pichia kudriavzevii-H-KKU20 was classified as a Crabtree-negative group; the ability to propagate cells is greater than for the Crabtree-positive group because glucose utilization is high. Crabtree-negative yeasts can transport glucose by an inducible high-affinity proton symport mechanism. Aerobic conditions especially provide steady growth conditions ${ }^{38}$.

The present results clearly indicate that $S$. cerevisiae could produce alcohol when used as an inoculant in a high concentration of carbon source under aerobic conditions. Under aerobic conditions, after $72 \mathrm{~h}$, S. cerevisiae produced $78.6 \mathrm{~g} / \mathrm{L}$ ethanol, which was more than other species produced. The high ethanol production capability of $S$. cerevisiae occurs because when its inoculant in media solution contained high sugar, the pyruvate dehydrogenase complex enzyme was inhibited ${ }^{31}$, but the activated pyruvate decarboxylase (about 3-4 times) was activated instead and change sugar to ethanol (although sufficient oxygen) ${ }^{39}$. In the present study, the high level of molasses at $250 \mathrm{~g} / \mathrm{kg}$ under aerobic conditions could also have allowed S. cerevisiae to produce higher ethanol concentration compared to other yeast species.

The sugar consumption by yeasts is related to the growth curve and depends on the yeast species $^{40}$. It was indicated that isolated yeast strains from rumen have a higher growth curve than Crabtree-positive yeast such as $S$. cerevisiae. This experiment revealed that $P$. kudriavzevii-H-KKU20 consumed more sugar by $133.1 \mathrm{~g}$ during 0 to $72 \mathrm{~h}$ of incubation than 
did S. cerevisiae, which consumed only by $124.6 \mathrm{~g}$ of sugar. Van Urk et al. ${ }^{29}$ stated that the sugar consumption rate of a pyruvate decarboxylase-deficient mutant of $S$. cerevisiae is much lower than that of Crabtree-negative yeast strains, indicating that pyruvate decarboxylase could have a strong influence on the glycolytic flux.

Based on the present study, it could be concluded that screening and isolating yeast from rumen fluid resulted in 11 different characteristics of yeasts. The first new yeasts discovered in the rumen fluid of dairy cattle were Pichia kudriavzevii-H-KKU20, Candida tropicalis-IKKU20, and Galactomyces sp.-C-KKU20, which could have potential for high production of yeast biomass and cellulase. The maximum growth of isolated yeast was shown in a media solution of $250 \mathrm{~g} / \mathrm{L}$ of sugarcane molasses and $10 \mathrm{~g} / \mathrm{L}$ of urea with pH 3.5 and $150 \mathrm{rpm}$ shaking. Under these circumstances, $P$. kudriavzevii-H-KKU20 had higher results than the other yeasts in terms of biomass production, cellulase enzyme activity, and cell number. This species may lead to higher production of yeast cell wall than the traditional species in yeast industry (such as $S$. cerevisiae) or in other applications as ruminant feed additives. However, evaluation of

Pichia kudriavzevii-H-KKU20's ability in fiber improvement and yeast biomass production needs to be elucidated to obtain increased nutritive value for ruminant animals. accordance with the relevant guidelines and regulations.

\section{Methods}

Animals involved in this study were approved by the Animal Ethics Committee of Khon Kaen University (record no. IACUC-KKU 38/62), the certificate that enables designing and carrying out animal experimentation under the Ethics of Animal Experimentation of National Research Council of Thailand. In addition, we confirmed that all methods were performed in

\section{Experiment 1}




\section{Animals and diet}

Experiment 1was conducted at Tropical Feed Resources Research and Development Center (TROFREC), Department of Animal Science, Faculty of Agriculture, Khon Kaen University (KKU), Thailand. Two fistulated-crossbred Holstein Friesian steers, averaging $350 \pm 20 \mathrm{~kg}$ body weight, were used to screen and isolate ruminal yeast.

Rumen fluid from the concentrate (crude protein (CP) $160.0 \mathrm{~g} / \mathrm{kg} \mathrm{DM}$ and total digestible nutrient (TDN) $750.0 \mathrm{~g} / \mathrm{kg} \mathrm{DM}$ ) fed dairy steers were obtained at $50 \mathrm{~g} / \mathrm{kg}$ of body weight (BW) in two equal portions at 07.00 and 16.00, and rice straw was fed on an ad libitum basis. The animals were held in individual cages and provided clean, fresh water and mineral blocks ad libitum. The animals were fed this diet for 7 days before the rumen fluid was obtained.

\section{The screening and isolation}

Screening and isolation of yeast were done according to Sirisan ${ }^{9}$. Briefly, the ruminal fluid from each fistulated steer was taken via rumen cannula at $4 \mathrm{~h}$ after the morning feeding and placed immediately on ice. For the total plate count, $1 \mathrm{ml}$ of ruminal fluid from each animal was diluted to $1: 10,1: 100$, and 1:1,000. Each ruminal fluid dilution was spread over a yeastmalt (YM) extract agar (HiMedia Laboratories Pvt. Ltd, Mumbai, Maharashtra, India) which was then incubated at $39{ }^{\circ} \mathrm{C}$ for $72 \mathrm{~h}$. All of these were dissolved in distilled water and sterilized for $15 \mathrm{~min}$ at $121^{\circ} \mathrm{C}$ by autoclaving. The $\mathrm{YM}$ agar consisted of malt extract ( $\left.3 \mathrm{~g} / \mathrm{L}\right)$, yeast extract (3 $\mathrm{g} / \mathrm{L})$, peptone $(5 \mathrm{~g} / \mathrm{L})$, agar $(20 \mathrm{~g} / \mathrm{L})$, and glucose $(10 \mathrm{~g} / \mathrm{L})$ and the $\mathrm{YM}$ broth was the same formulation without agar. A reference strain of Saccharomyces cerevisiae obtained from commercial product (Greathill Co., Ltd., Bangkok, Thailand) was used for comparison.

\section{Morphological characterization}



were examined under a 40x light microscope. By studying different morphological characteristics $^{10}$, the isolated yeast strains were identified. The appearances of the yeast colonies were recorded: size, shape, convexity, surface, and color of colonies for purification. Colonies growing along the points of the streak were picked up, purified, regrown in a YM broth (HiMedia Laboratories Pvt. Ltd, Mumbai, Maharashtra, India), and kept in the

refrigerator at $4^{\circ} \mathrm{C}$ as stock colonies of yeasts. Afterward, all isolates were subjected to an initial assessment to determine their yeast biomass and cellulase production ability by inoculating them in different solutions of sugarcane molasses, urea, and CMC. For further evaluation, the top three strains of isolated yeast showing the largest production of yeast biomass or cellulase were selected.

\section{Determination of the yeast biomass and carboxymethyl cellulase activity}

Experimental design and preparation of media solution 3 factorial was used in a completely randomized design. Factor A was isolated yeast at A, B, C, D, E, F, G, H, I, J, K codes and S. cerevisiae. Factor B was sugarcane molasses concentration at 50,100 , and $250 \mathrm{~g} / \mathrm{L}$ distilled water. Factor $\mathrm{C}$ was urea concentration at 10,30 , and $50 \mathrm{~g} / \mathrm{L}$ distilled water. Fermentation media were prepared by addition of sugarcane molasses as a carbon source (Khon Kaen Dairy cooperative Co., Ltd., Khon Kaen, Thailand), urea as a nitrogen source (Saengtawee Panit Co., Ltd., Khon Kaen, Thailand), and carboxymethyl 
cellulose (CMC) $10 \mathrm{~g} / \mathrm{L}$ distilled water as a stimulant substrate (Chemipan Co., Ltd., Bangkok, Thailand). $\mathrm{H}_{2} \mathrm{SO}_{4} 70 \%$ was added to adjust to a $\mathrm{pH}$ of 3.5 . The media solution was placed in $250 \mathrm{ml}$ Erlenmeyer flasks. The flasks were filled to $100 \mathrm{ml}$, and $1 \mathrm{ml}$ of isolated homogenous yeast suspension from rumen (about $10^{6}$ cells per $\mathrm{ml}$ ) was inoculated into the media solution in an aseptic condition. Flasks were cotton plugged before incubation in an incubator-shaker machine ${ }^{8}$.

The different levels of sugarcane molasses and urea were prepared with $100 \mathrm{ml}$ of solution in 250 Erlenmeyer flask by adding a single colony from stock culture of all isolated and $S$. cerevisiae start culture $\left(10^{6}\right.$ cells) to fermentation media. After that, the cultures were inoculated in an incubator shaker at $30{ }^{\circ} \mathrm{C}$ at $150 \mathrm{rpm}$ for $72 \mathrm{~h}$. One milliliter of fluid culture was collected at $0,6,12,18,24,30,36,48,60$, and $72 \mathrm{~h}$ of incubation. The $\mathrm{pH}$, cell count,

Yeast biomass production from isolated strains

Yeast biomass was determined following Johnson et al. ${ }^{12}$. A $1 \mathrm{ml}$ cultured liquid sample was centrifuged at room temperature at $10,000 \mathrm{~g}$ for $10 \mathrm{~min}$. Cell pellets were washed with 
distilled water and then dried at $105^{\circ} \mathrm{C}$ until the weight remained constant. Duplicate samples were tested.

Estimation of reducing sugar and carboxymethyl cellulase activity of isolated yeast strains The activity of carboxymethyl cellulase was determined using 3,5-Dinitrosalicylic acid (DNS) reagent by the colorimetric method according to Miller ${ }^{13}: 0.5 \mathrm{ml}$ of crude supernatant was applied to $0.5 \mathrm{ml}$ of $1 \%$ (w/v) CMC solution. This solution was inserted into a $0.05 \mathrm{M}$ citrate phosphate buffer, ( $\mathrm{pH} 4.0)$ and incubated at $45{ }^{\circ} \mathrm{C}$ for $30 \mathrm{~min}^{14}$. The enzymatic reaction was interrupted by adding $1.0 \mathrm{ml}$ DNS reagent and putting it in a boiling water bath for $10 \mathrm{~min}$. A spectrophotometer measured the color of the reaction product as $540 \mathrm{~nm}$. One enzyme unit was defined as the quantity of enzyme that hydrolyzed CMC to produce $1 \mu$ mol of sugar per minute under the experimental condition. The equation is derived from the glucose-equivalent factor generated in the assay to mmol of glucose, from the volume of the enzyme being tested in the assay $(0.5 \mathrm{ml})$ and the incubation time $(30 \mathrm{~min})$ required for generation of the reducing equivalents ${ }^{15}$.

$$
\text { Carboxymethyl cellulase activity }(\mathrm{Unit} / \mathrm{ml})=(\mathrm{C} \times \mathrm{D}) \div \mathrm{MTV}
$$

Then: $\mathrm{C}=$ Releasing glucose from cellulase $(\mathrm{mg})$

$\mathrm{D}=$ Dilution factor of enzyme

$\mathrm{M}=$ Glucose molecular weight $(180 \mathrm{~g} / \mathrm{mol})$

$\mathrm{T}=$ Time incubation

$\mathrm{V}=$ Enzyme volume

\section{Experiment 2}

Cell count, ethanol production and reducing sugar by ruminal yeast strains

\section{Experimental design}



cellulase enzyme. The potential yeast was selected for identified and analyzed as a $7 \times 4$ factorial use in a completely randomized design including. Factor A was incubation time at 0 , $12,24,36,48,60$, and $72 \mathrm{~h}$. Factor B was isolated yeast strains including code H-KKU20 (as P. kudriavzevii-KKU20), I-KKU20 (C. tropicalis-KKU20), C-KKU20 (as Galactomyces sp.KKU20), and S. cerevisiae. Media solutions were prepared following the appropriate solution for potential yeast, yeast biomass, and CMCase activity.

\section{Measurement of yeast cell growth by direct count technique} urea media culture, via counting method using a hemocytometer under microscope according to Darvishi et al. ${ }^{16}$.

\section{Ethanol production from isolated yeasts}

Ethanol concentration in the fermentation media (molasses $250 \mathrm{~g} / \mathrm{L}$ and urea $10 \mathrm{~g} / \mathrm{L}$ ) was determined by an Agilent 7890B gas chromatographer (Agilent Corporation, California, USA). The standard water-based ethanol solutions were prepared from $0.0-1.0 \%(\mathrm{v} / \mathrm{v})$, and 1quantitative ethanol analysis using a capillary columnHP-5 (length $30 \mathrm{~m}$ ) on a GC apparatus; oven temperature $40{ }^{\circ} \mathrm{C}$ constant flow mode with a Flame Ionization Detector (FID) $300{ }^{\circ} \mathrm{C}$, air flow of $350 \mathrm{ml} / \mathrm{min}$, and inlet temperature of $150{ }^{\circ} \mathrm{C}$ were used ${ }^{17}$.

\section{Reducing sugar from isolated yeasts}

The reducing sugar was determined using the DNS method ${ }^{13}$. To measure absorbance, 
and after fermentation was determined by applying $1.0 \mathrm{ml}$ diluted solution $(1 \mathrm{ml}$ sample in 9

397

398

399

400

401

402

403

404

405

406

407

408

409

410

411

412

413

414

415

416

417

418

419

420

$\mathrm{ml}$ distilled water) to a test tube with $1.0 \mathrm{ml}$ DNS reagent. A blank was run in parallel with 1.0 $\mathrm{ml}$ of distilled water and $1.0 \mathrm{ml}$ of DNS. The tubes were heated for $15 \mathrm{~min}$ in a bath of boiling bath water. Using a spectrophotometer, $5 \mathrm{ml}$ of distilled water was applied after the tubes were cooled at room temperature, and absorbance values were noted at $540 \mathrm{~nm}$. Reduction of the sugar concentration was determined from the standard glucose curve and by the dilution factor multiples ${ }^{18}$.

\section{Molecular identification of selected ruminal yeast}

\section{Isolation of DNA for polymerase chain reaction}

DNA isolation was performed by boiling lysis buffer cells according to Maniatis et al. ${ }^{19}$ with slight modification. A loopful of yeast cells was transferred to a $1.5 \mathrm{ml}$ Eppendorf tube and $100 \mu \mathrm{l}$ of lysis buffer was added. The cells were suspended in the distilled water and heated at $95^{\circ} \mathrm{C}$ for $15 \mathrm{~min}$ in a metal block bath. After boiling, $100 \mu \mathrm{l}$ of $2.5 \mathrm{M}$ potassium acetate $(\mathrm{pH}$ 7.5) was added and placed on ice for $1 \mathrm{~h}$, then centrifuge for $5 \mathrm{~min}$ at 14,000 rpm. Supernatant was extracted from isoamyl alcohol twice with $100 \mu 1$ of chloroform $(24: 1 \mathrm{v} / \mathrm{v})$. DNA was precipitated with isopropanol, placed on hold for $10 \mathrm{~min}$ at $20^{\circ} \mathrm{C}$, and centrifuged for 15 min at 15,000 rpm. DNA pellets were rinsed with $70 \%$ ethanol and $90 \%$ ethanol, then dried at room temperature for 15-30 min. The dried DNA was dissolved in $30 \mu 1$ Milli-Q purified water.

Polymerase chain reaction (PCR) for D1/D2 domain of $26 \mathrm{~S}$ rDNA

The divergent D1/D2 domain of 26S rDNA was amplified with primers NL-1 (5'- GCA TAT CAA TAA GCG GAG GAA AAG-3') and NL4 (5'-GGT CCG TGT TTC AAG ACG G$\left.3^{\prime}\right)^{10}$. Amplification was performed in $100 \mu \mathrm{l}$ reaction mixture conditioning $100 \mathrm{ng}$ of $2.5 \mathrm{U}$ of Taq polymerase, genomic DNA, $40 \mathrm{mM}$ of each primer, $20 \mathrm{mM}$ of each dNTP, $1.5 \mathrm{mM} \mathrm{MgCl} 2$, 
and $10 \mathrm{mM}$ Tris- $\mathrm{HCl}$. The reaction was pre-denatured at $94{ }^{\circ} \mathrm{C}$ for $5 \mathrm{~min}$. This was repeated

422

423

424 at $94^{\circ} \mathrm{C}$ for $1 \mathrm{~min}$ for $30 \mathrm{PCR}$ cycles, annealed at $55^{\circ} \mathrm{C}$ for $1 \mathrm{~min}$, and extension at $72{ }^{\circ} \mathrm{C}$ for $2.5 \mathrm{~min}$, followed by the final extension at $72{ }^{\circ} \mathrm{C}$ for $10 \mathrm{~min}$.. According to manufacturer instructions, the amplified DNA was purified with a QIAquick PCR purification kit. Visualization of purified amplified DNA was accomplished by electrophoresis using $0.8 \%$ agarose gel in $1 \mathrm{X}$ TBE buffer and stained with ethidium bromide $\left(8 \times 10^{-5} \mu \mathrm{g} / \mathrm{ml}\right)$ and observed under a UV illuminator.

\section{D1/D2 domain of $26 S$ rDNA sequencing}

The nucleotide sequences of the 26S rDNA domain D1/D2 were determined directly using PCR products according to Kurtzman and Robnett ${ }^{10}$ with slight modification. Cycle sequencing of the D1/D2 domain was used with the forward primer NL1 (5'-GCA TAT CAA TAA GCG GAG GAA AAG-3') and reverse primer, NL4 (5'-GGT CCG TGT TTC AAG ACG G-3'), by ABI PrismTM BigDye ${ }^{\mathrm{TM}}$ Terminator Cycle Sequence Ready Reaction Kit (Applied Biosystems, Stafford, USA) according to the manufacturer's instruction and delivered to National Center for Genetics Engineering and Biotechnology (BIOTECH, Khlong Luang, Pathum Thani, Thailand) for sequencing. The sequences aliment with CLUSTAL X program and were compared with GenBank DNA database (http:// www.ncbi.nlm.nih.gov/)

\section{Statistical analysis}

Experiment 1. Data were analyzed as a $12 \times 3 \times 3$ factorial in a completely randomized design. The analysis of variance procedure of SAS program was used for the analysis and the statistical model is as follows:

$$
Y_{i j k}=\mu+A_{i}+B_{j}+A B_{i j}+C_{k}+A C_{i k}+B C_{j k}+A B C_{i j k}+\varepsilon_{i j k}
$$


Where $Y_{i j k}=$ observation, $\mu=$ overall mean, $A_{i}=$ Yeast strain effect $(\mathrm{i}=\mathrm{a}, \mathrm{b}, \mathrm{c}, \mathrm{d}, \mathrm{e}, \mathrm{f}, \mathrm{g}$,

$\mathrm{h}, \mathrm{i}, \mathrm{j}, \mathrm{k}$ and $S$. cerevisiae $), B_{j}=$ sugarcane molasses effect $(\mathrm{j}=50,150$ and $250 \mathrm{~g} / \mathrm{kg}), A B_{i j}=$ yeast

strain effect $\times$ sugarcane molasses effect, $C_{k}=$ urea effect $(\mathrm{k}=10,30$ and $50 \mathrm{~g} / \mathrm{kg}), A C_{i k}=$ yeast

strain effect $\times$ urea effect, $B C_{j k}=$ sugarcane molasses effect $\times$ urea effect, $A B C_{i j k}=$ yeast strain effect $\times$ sugarcane molasses $\times$ urea effect and $\varepsilon_{i j k}=$ error.

Experiment 2. Data were analyzed as a $7 \times 4$ factorial in a completely randomized design. The ANOVA procedure of SAS program was used for the analysis and the statistical model is as follows:

$$
Y_{i j}=\mu+A_{i}+B_{j}+A B_{i j}
$$

Where $\mathrm{Y}_{\mathrm{ijk}}=$ observation, $\mu=$ overall mean, $\mathrm{A}_{\mathrm{i}}=$ Incubation time effect $(\mathrm{i}=0,12,24$, 36, 48, 60 and $72 \mathrm{~h}), \mathrm{B}_{\mathrm{j}}=$ Isolated yeast strains effect $(\mathrm{j}=\mathrm{H}-\mathrm{KKU} 20$ (as P. kudriavzeviiKKU20), I-KKU20 (as C. tropicalis-KKU20), C-KKU20 (as Galactomyces sp.-KKU20), and

S. cerevisiae, $\mathrm{AB} i j=$ incubation time effect $\times$ isolated yeast strains effect and cijk $=$ error. of SAS. All experimental design was use with ANOVA by the General Linear Model (GLM) procedures of $\mathrm{SAS}^{20}$ (Version 6.0; SAS Institute Inc., Cary, NC, USA). When F-tests were significant, single degree of freedom orthogonal polynomial were used to determine trend of factors. The treatment mean differences were determined by Duncan's New Multiple Range Test (DMRT) at $\mathrm{P}=0.05^{21}$.

\section{References}

4661 Fonty, G. \& Chaucheyras-Durand, F. Effects and modes of action of live yeasts in the rumen. Biologia 61, 741-750 (2006).

4682 Chiquette, J. in 30 th Western Nutrition Conference. 143-157. 
4693 Sirisan, V., Pattarajinda, V., Vichitphan, K. \& Leesing, R. Isolation, identification and 470 growth determination of lactic acid-utilizing yeasts from the ruminal fluid of dairy cattle. $471 \quad$ Letters in applied microbiology 57, 102-107 (2013).

4724 Hasunuma, $\mathrm{T}$. et al. Consecutive reticular $\mathrm{pH}$ monitoring in dairy cows fed diets 473 supplemented with active dry yeast during the transition and mid-lactation periods. $474 \quad$ Animal Feed Science and Technology 221, 215-225 (2016).

4755 Paserakung, A., Pattarajinda, V., Vichitphan, K. \& Froetschel, M. Selection and 476 identification of oleaginous yeast isolated from soil, animal feed and ruminal fluid for 477 use as feed supplement in dairy cattle. Letters in applied microbiology 61, 325-332 $478 \quad(2015)$

4796 Intanoo, M. et al. Isolation and screening of aflatoxin-detoxifying yeast and bacteria from ruminal fluids to reduce aflatoxin B1 contamination in dairy cattle feed. Journal of applied microbiology 125, 1603-1613 (2018).

4827 Dennis, C. Breakdown of cellulose by yeast species. Microbiology 71, 409-411 (1972).

4838 Sarawan, S., P. Mahakhan, S. Jindamorakot, K. Vichitphan, S. Vichitphan and J. 484 Sawaengkaew. Candida konsanensis sp. nov., a new yeast species isolated from 485 Jasminum adenophyllum in Thailand with potentially carboxymethyl cellulase486 producing capability. World. J. Microb. Biot. 29, 1481-1486 (2013).

4879 Sirisan, V. Screening and identification of lactic acid utilizing yeasts in the rumen by 488 molecular technique for increasing dairy cattle performance $\mathrm{PhD}$ thesis, Khonkaen $489 \quad$ university, (2013).

49010 Kurtzman, C. P. \& Robnett, C. J. Identification and phylogeny of ascomycetous yeasts 491 from analysis of nuclear large subunit (26S) ribosomal DNA partial sequences. Antonie 492 van Leeuwenhoek 73, 331-371 (1998). 
49311 Khampa, S., Chuelong, S., Kosonkittiumporn, S. \& Khejornsart, P. Manipulation of yeast 494 fermented cassava chip supplementation in dairy heifer raised under tropical condition. $495 \quad$ Pak J Nutr 9, 950-954 (2010).

49612 Johnson, V. W. et al. Utilization of molasses for the production of fat by an oleaginous 497 yeast, Rhodotorula glutinis IIP-30. Journal of industrial microbiology 14, 1-4 (1995).

49813 Miller, G. Modified DNS method for reducing sugars. Anal Chem 31, 426-428 (1959).

49914 Sengupta, S., Jana, M., Sengupta, D. \& Naskar, A. A note on the estimation of microbial 500 glycosidase activities by dinitrosalicylic acid reagent. Applied microbiology and 501 biotechnology 53, 732-735 (2000).

50215 Mandel, M. Exoglucanase activity by microorganisms. Adv Chem 95, 391-414 (1969).

50316 Darvishi, F., Moradi, M., Madzak, C. \& Jolivalt, C. Production of laccase by recombinant $504 \quad$ Yarrowia lipolytica from molasses: bioprocess development using statistical modeling 505 and increase productivity in shake-flask and bioreactor cultures. Applied biochemistry $506 \quad$ and biotechnology 181, 1228-1239 (2017).

50717 Luangkriangkrai, a. S. I., C. in Agricultural conference.

50818 Ghose, T. Measurement of cellulase activities. Pure and applied Chemistry 59, 257-268 $509 \quad$ (1987).

51019 Maniatis, T., Fritsch, E. t. \& Sambrrok, J. (Cold Spring Harbor Laboratory, Cold Spring $511 \quad$ Harbor, NY, 1982).

51220 User's Guide: Statistic v. Version 6 (Cary, NC., 1989).

51321 Steel, R. G. \& Torrie, J. H. Principles and Procedures of Statistics McGraw-Hill Book $514 \quad$ Co. Inc., New York 633 (1980).

51522 Orpin, C. Studies on the rumen flagellate Neocallimastix frontalis. Microbiology 91, 249516 $262(1975)$. 
23 Marrero, Y. et al. Morphological, biochemical and molecular identification of the yeast Levica 25: A Potential Ruminal Microbial Additive. Global Veterinaria 7, 60-65 (2011).

24 Marrero, Y. et al. Identification of Levica yeasts as a potential ruminal microbial additive. Czech Journal of Animal Science 58, 460-469 (2013).

25 Tefera, T., Ameha, K. \& Biruhtesfa, A. Cassava based foods: microbial fermentation by single starter culture towards cyanide reduction, protein enhancement and palatability. International food research Journal 21, 1751 (2014).

26 Manikandan, K. \& Viruthagiri, T. Optimization of $\mathrm{C} / \mathrm{N}$ ratio of the medium and fermentation conditions of ethanol production from tapioca starch using co-culture of Aspergillus niger and Saccharomyces cerevisiae. Int J Chem Tech Res 2, 947-955 (2010).

27 Danesi, E. D. G., Miguel, Â. S. M., de Oliveira Rangel-Yagui, C., De Carvalho, J. C. M. \& Pessoa Jr, A. Effect of carbon: nitrogen ratio (C: N) and substrate source on glucose6-phosphate dehydrogenase (G6PDH) production by recombinant Saccharomyces cerevisiae. Journal of Food Engineering 75, 96-103 (2006).

28 Sokchea, H., Thi Hang, P., Dinh Phung, L., Duc Ngoan, L. \& Thu Hong, T. Effect of Time, Urea and Molasses Concentration on Saccharomyces Cerevisiae Biomass Production. J Vet Ani Res 1, 104 (2018).

29 Van Urk, H., Voll, W. L., Scheffers, W. A. \& Van Dijken, J. P. Transient-state analysis of metabolic fluxes in Crabtree-positive and Crabtree-negative yeasts. Appl. Environ. Microbiol. 56, 281-287 (1990).

30 Wardrop, F., Liti, G., Cardinali, G. \& Walker, G. Physiological responses of Crabtree positive and Crabtree negative yeasts to glucose upshifts in a chemostat. Annals of microbiology 54, 103-114 (2004).

31 Dashko, S., Zhou, N., Compagno, C. \& Piškur, J. Why, when, and how did yeast evolve alcoholic fermentation? FEMS yeast research 14, 826-832 (2014). 
54232 Lynd, L. R., Weimer, P. J., Van Zyl, W. H. \& Pretorius, I. S. Microbial cellulose 543 utilization: fundamentals and biotechnology. Microbiol. Mol. Biol. Rev. 66, 506-577 $544 \quad(2002)$.

54533 Ilmén, M. et al. High level secretion of cellobiohydrolases by Saccharomyces cerevisiae. $546 \quad$ Biotechnology for biofuels 4, 30 (2011).

54734 Du Plessis, L., Rose, S. H. \& van Zyl, W. H. Exploring improved endoglucanase 548 expression in Saccharomyces cerevisiae strains. Applied microbiology and $549 \quad$ biotechnology 86, 1503-1511 (2010).

55035 Lund, A. Yeasts and moulds in the bovine rumen. Microbiology 81, 453-462 (1974).

55136 Priji, P., Unni, K., Sajith, S. \& Benjamin, S. Candida tropicalis BPU1, a novel isolate from the rumen of the Malabari goat, is a dual producer of biosurfactant and polyhydroxybutyrate. Yeast 30, 103-110 (2013).

37 Shin, E. et al. Phylogenetic analysis of yeast in the rumen contents of cattle based on the 26S rDNA sequence. The Journal of Agricultural Science 142, 603-611 (2004).

38 Pronk, J. T., Yde Steensma, H. \& van Dijken, J. P. Pyruvate metabolism in Saccharomyces cerevisiae. Yeast 12, 1607-1633 (1996).

39 Piškur, J. \& Compagno, C. Molecular mechanisms in yeast carbon metabolism. 333 ( Springer; 2014th Edition (May 6, 2014), 2014).

40 van Dijken, J. P., Weusthuis, R. A. \& Pronk, J. T. Kinetics of growth and sugar consumption in yeasts. Antonie van leeuwenhoek 63, 343-352 (1993).

Acknowledgments

The authors would like to express our sincere thanks to the Royal Golden Jubilee Ph.D. 
567 Khon Kaen University for providing finalities supports. Special thanks to the Tropical Feed 568 Resources Research and Development Center (TROFEC), Department of Animal Science, 569 Faculty of Agriculture, Khon Kaen University, KKU and the Fermentation Research Center 570 for Value Added Agricultural Products (FerVAAP) for the use of research facilities.

571

572 Author contributions

573 C. Suntara, A. Cherdthong, V. Leelavatcharamas, and J. Sawaengkeaw: Investigation, 574 Methodology; C. Suntara, A. Cherdthong, M. Wanapat and J. Sawaengkeaw: Data curation, 575 Formal analysis, Software, and Project administration, Conceptualization, Methodology, and 576 Project administration, Funding acquisition; C. Suntara A. Cherdthong, and S. Uriyapongson: 577 Resources, Supervision, Validation; Visualization; C. Suntara: Roles/Writing - original draft; 578 C. Suntara, A. Cherdthong, J. Sawaengkeaw, P. Chanjula and S. Foiklang: Writing - review \& 579 editing. All authors have read and agreed to the published version of the manuscript.

581 Competing interests

582 The authors declare no conflict of interest. 


\section{Figures}

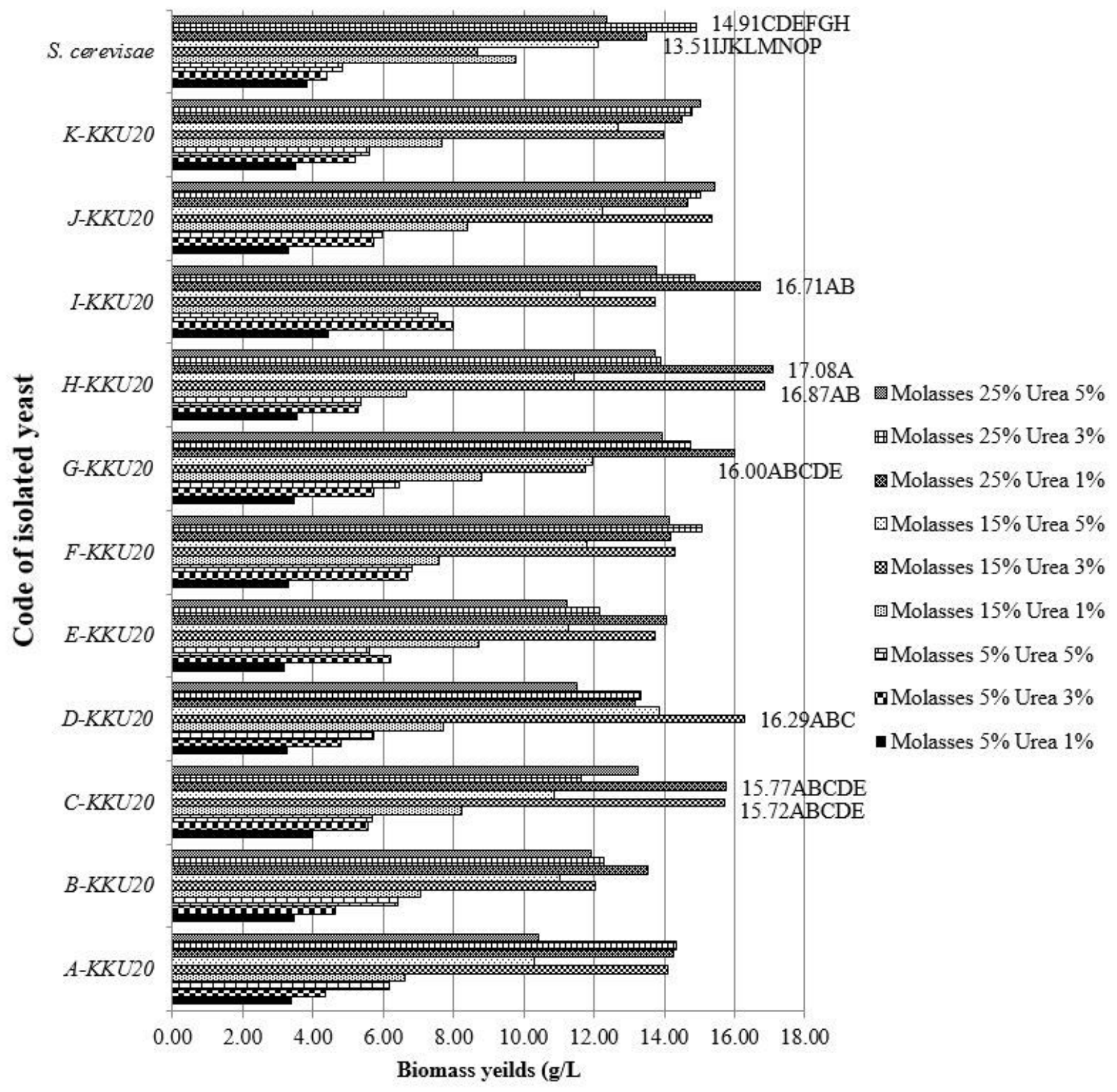

\section{Figure 1}

Biomass (horizontal axis) for yeast strains grown in different sugarcane molasses (50, 150 and 250 $\mathrm{g} / \mathrm{kg}$ ) with urea $(10,30$ and $50 \mathrm{~g} / \mathrm{kg})$ for $72 \mathrm{~h} . \mathrm{A}, \mathrm{B}, \mathrm{C}, \mathrm{D}, \mathrm{E}$ values within a chart show significant different at $\mathrm{P}<0.01$. 


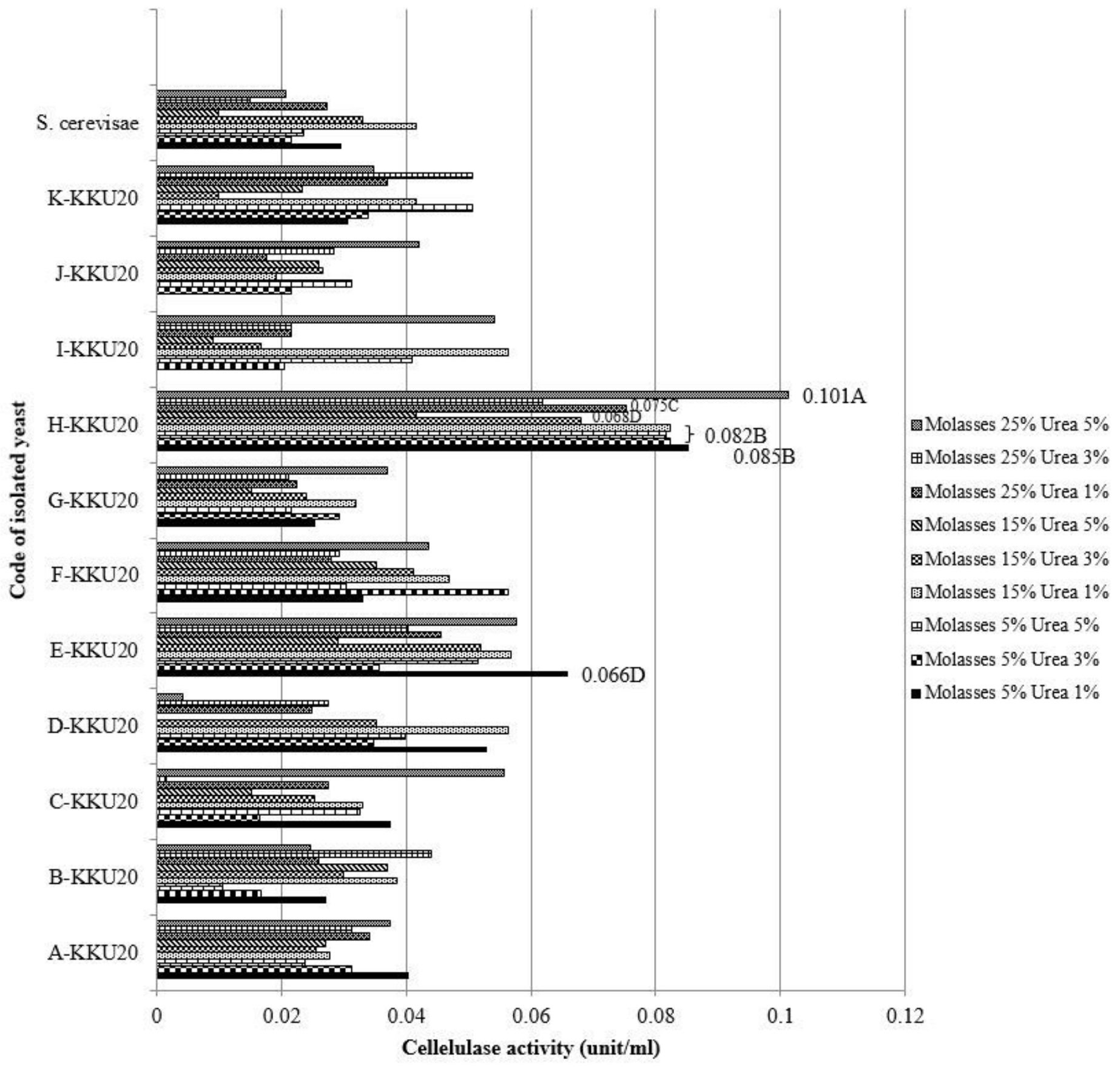

Figure 2

Effect of $\mathrm{CMC}$ concentration from $1 \%(\mathrm{w} / \mathrm{v})$ on cellulase production of each rumen fluids isolates yeast at 72 h. A, B, C, D values within a chart show significant different at $P<0.01$. 


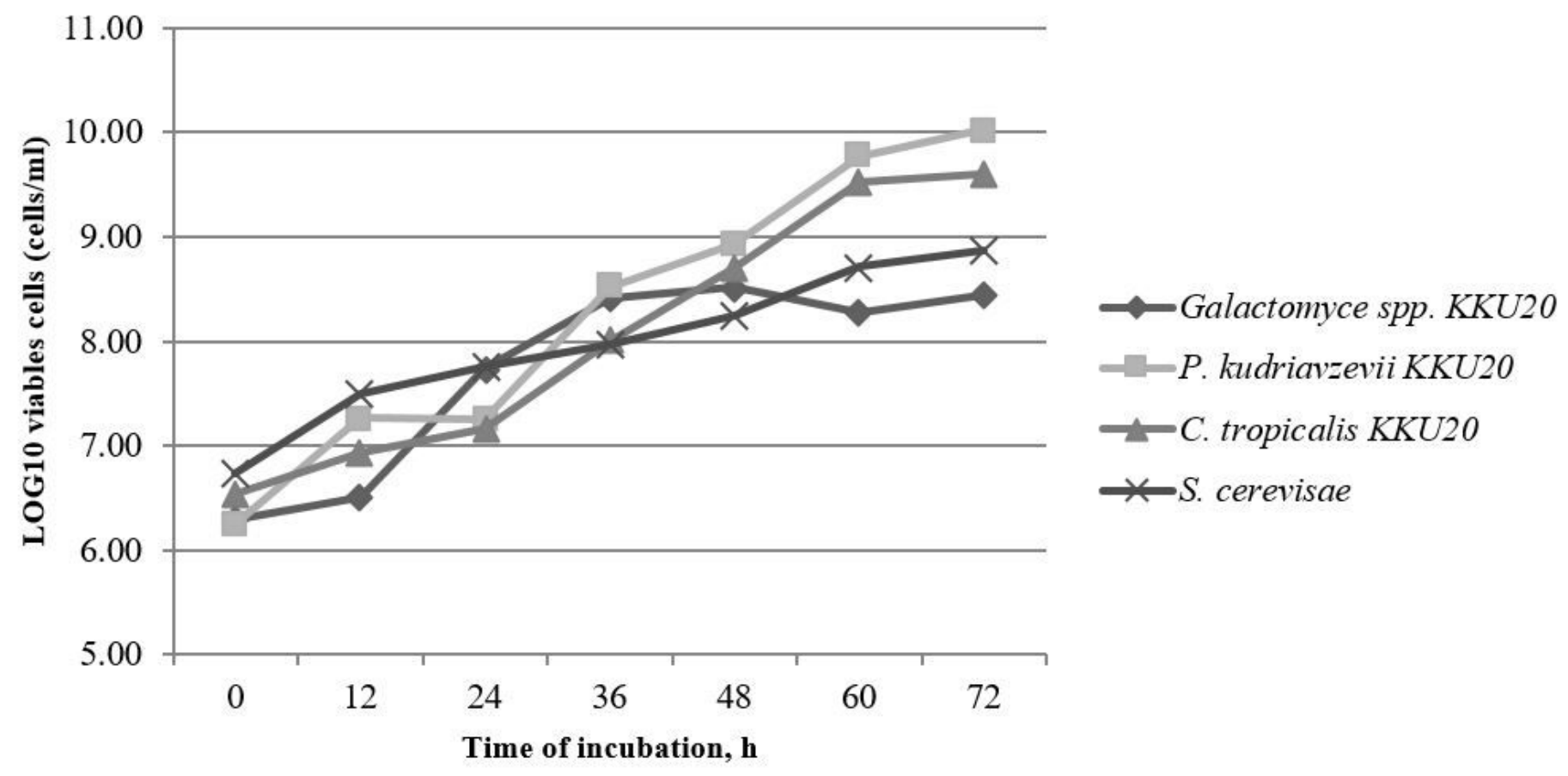

Figure 3

Viable cells count from batch fermentation under sugarcane molasses $250 \mathrm{~g} / \mathrm{kg}$ with urea $10 \mathrm{~g} / \mathrm{kg}$ plus $10 \mathrm{~g} / \mathrm{kg} \mathrm{CMCase}$ in the incubator shaker at 30 degrees oC at $150 \mathrm{rpm}$ for $72 \mathrm{~h}$.

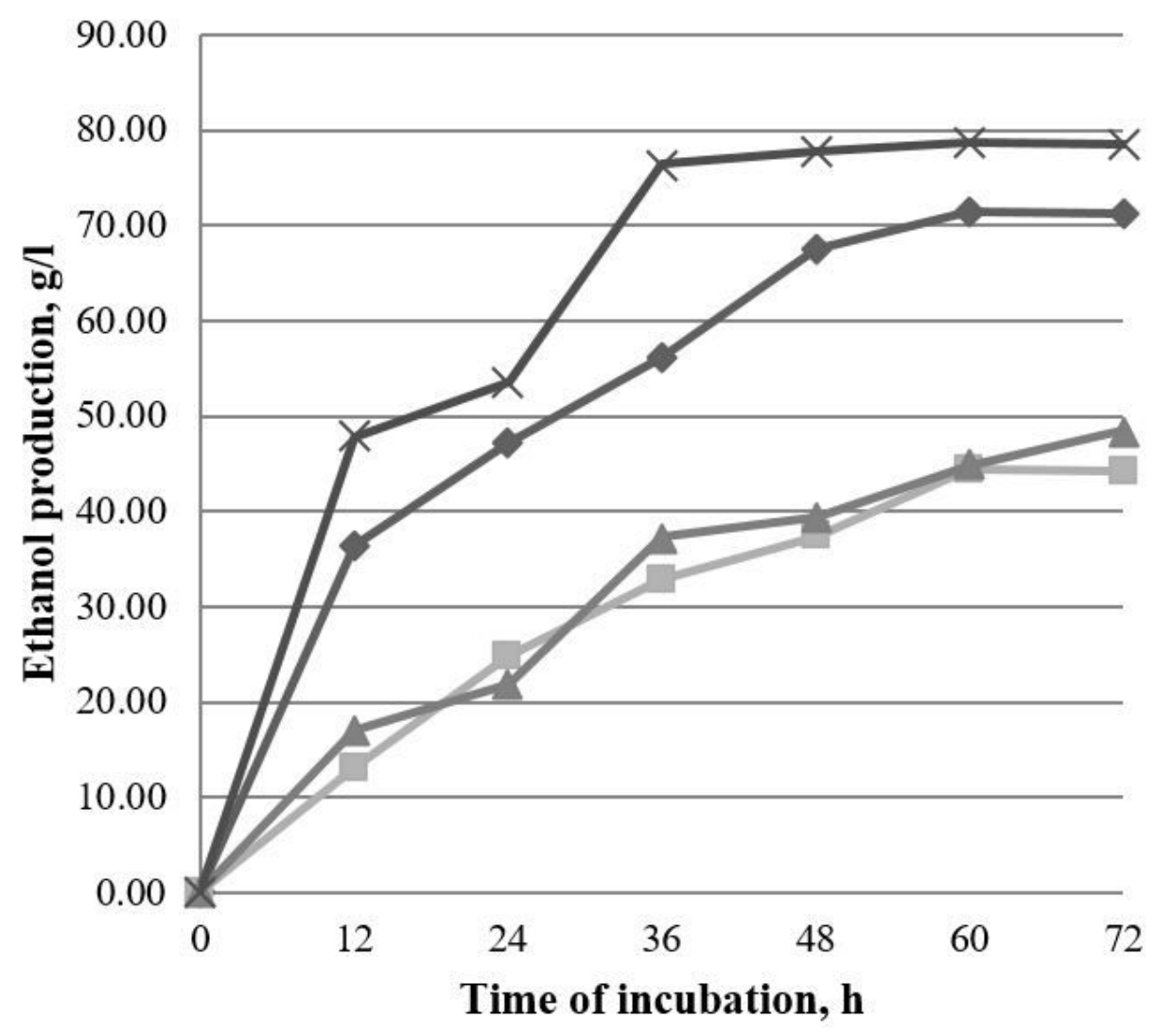

-Galactomyce spp. KKU20

- -P. kudriavzevii KKU20

- C. tropicalis KKU20

$*$ S. cerevisae 


\section{Figure 4}

The production of ethanol by four different yeast strains under sugarcane molasses $250 \mathrm{~g} / \mathrm{kg}$ with urea $10 \mathrm{~g} / \mathrm{kg}$ plus $10 \mathrm{~g} / \mathrm{kg} \mathrm{CMC}$ in the incubator shaker at 30 degrees oC at $150 \mathrm{rpm}$ for $72 \mathrm{~h}$.

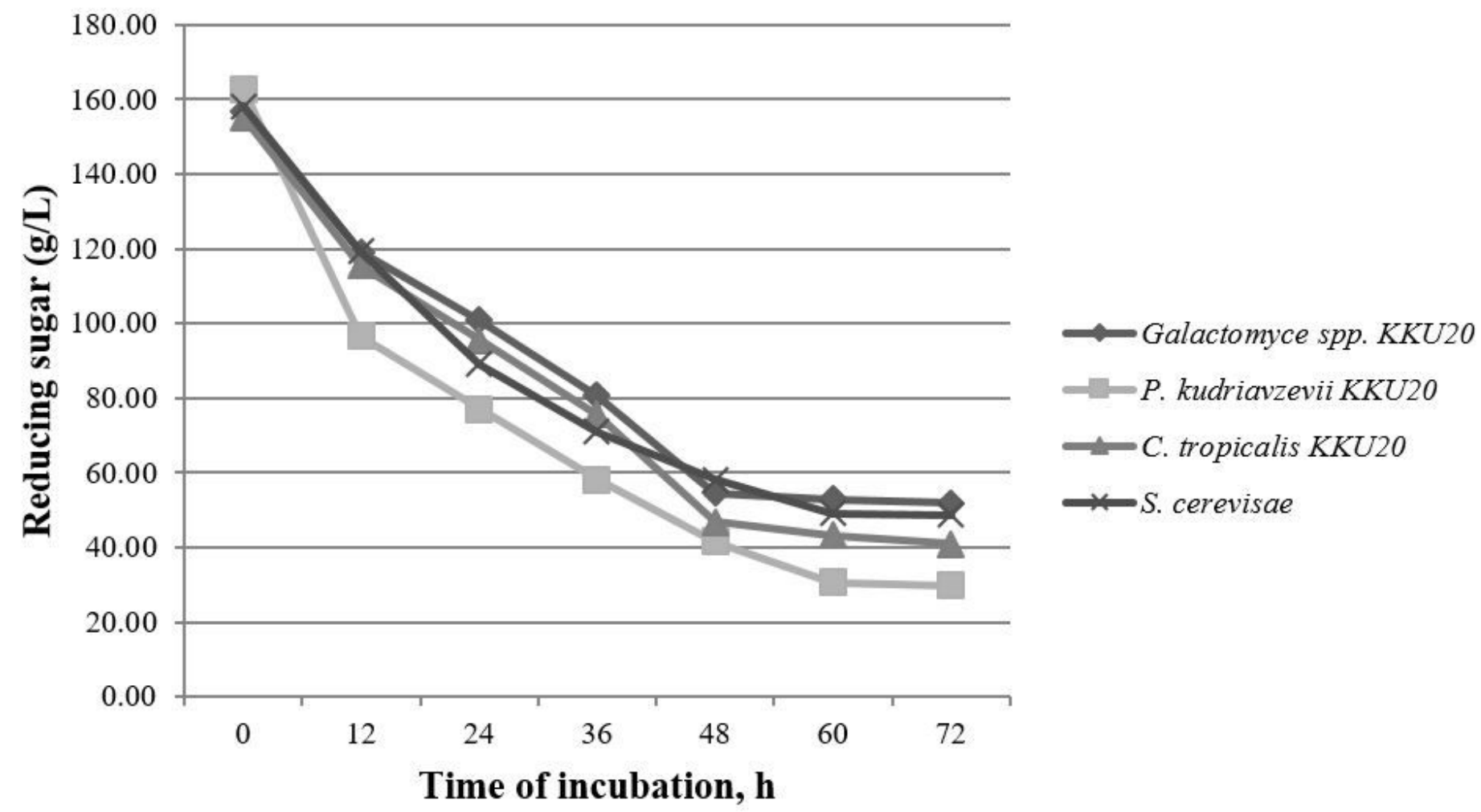

Figure 5

Sugar utilization by four different yeast strains under sugarcane molasses $250 \mathrm{~g} / \mathrm{kg}$ with urea $10 \mathrm{~g} / \mathrm{kg}$ plus $10 \mathrm{~g} / \mathrm{kg} \mathrm{CMC}$ in the incubator shaker at 30 oC at $150 \mathrm{rpm}$ for $72 \mathrm{~h}$.

\section{Supplementary Files}

This is a list of supplementary files associated with this preprint. Click to download.

- TableScreenChanonSciencetificreports.docx 